Okada, Y., Hikita, T., Ishitobi, K., Wada, M., Santo, Y., and Harada, Y. (1972). Human growth hormone secretion after exercise and oral glucose administration in patients with short stature. Fournal of Clinical Endocrinology and Metabolism, 34, 1055.

J. M. H. BUCKLER

Department of Paediatrics and Child Health, University of Leeds, 27 Blundell Street, Leeds LS1 $3 E T$.

\section{Pica with rapid improvement after dietary zinc supplementation}

Recent evidence, derived primarily from measurements of hair zinc levels, has indicated that body zinc stores may be relatively low in infants and children less than 4 years of age in the United States (Hambidge et al., 1972). Moreover, the correlation observed between low hair zinc levels (70 p.p.m. or less), poor appetite, and low growth centiles suggested the occurrence of symptomatic zinc deficiency in some otherwise normal children. In the Middle East a high incidence of pica, manifested by geophagia, has been reported to occur in male adolescents who have evidence of severe symptomatic zinc deficiency (Prasad, Halsted, and Nadimi, 1961). It is not certain whether this geophagia was an aetiological factor contributing to the zinc deficiency, or if it was a feature attributable to a preceding deficiency of this essential micronutrient (Halsted et al., 1972). This report concerns an unusual case of pica which improved rapidly after starting dietary zinc supplementation.

\section{Case report}

A Caucasian female was the product of a normal pregnancy and delivery. Her birthweight was $3,300 \mathrm{~g}$ and length $51 \mathrm{~cm}$. Her mother's and father's heights were $163 \mathrm{~cm}$ and $185 \mathrm{~cm}$, respectively. Apart from her physical growth, her development was quite normal during infancy and she had no serious illnesses. Her weight centile, which was at the 50th until the age of 2 months, declined to the 3rd by 6 months of age, and subsequently remained at this centile (Fig.). Her height centile, which was on the 90th at 3 months of age, also declined in later infancy to the 25th by 11 months of age; and then, between 18 and 24 months, to the 10th centile. Her appetite was initially good and her early feeding habits were unremarkable. At 4 months of age she was taking $720 \mathrm{ml}$ milk formula and 3 meals of solid foods per day. However, from the age of 6 months her appetite was 'not so good', and at 18 months of age her mother reported a marked deterioration in appetite.

At the age of 18 months she began to eat metallic objects and, to a lesser extent, her own hair. These metallic objects, which she inserted into her mouth for extensive periods of time, included, for example, keys and aluminium foil. She was also observed to be gnawing frequently at the metal stripping on the edge of the carpets. Physical examination at the age of 24 months was unremarkable apart from her relatively poor growth and a marked silver discoloration of her teeth, the result of her unusual dietary habits. Her height was $82 \mathrm{~cm}$, weight $9.87 \mathrm{~kg}$, and haemoglobin $12.5 \mathrm{~g} / 100 \mathrm{ml}$. At this stage her hair was analysed (Hambidge, 1971) and the zinc concentration was 70 p.p.m. In view of this low level ( $>3$ SD below the mean for normal adults) (Hambidge et al., 1972) and her poor appetite and relatively poor growth, a therapeutic trial of dietary zinc supplementation was started. $5 \mathrm{ml}$ of a cherry-flavoured solution, containing $10 \mathrm{mg}$ zinc sulphate $\left(\mathrm{ZnSO}_{4} \times 7 \mathrm{H}_{2} \mathrm{O}\right.$

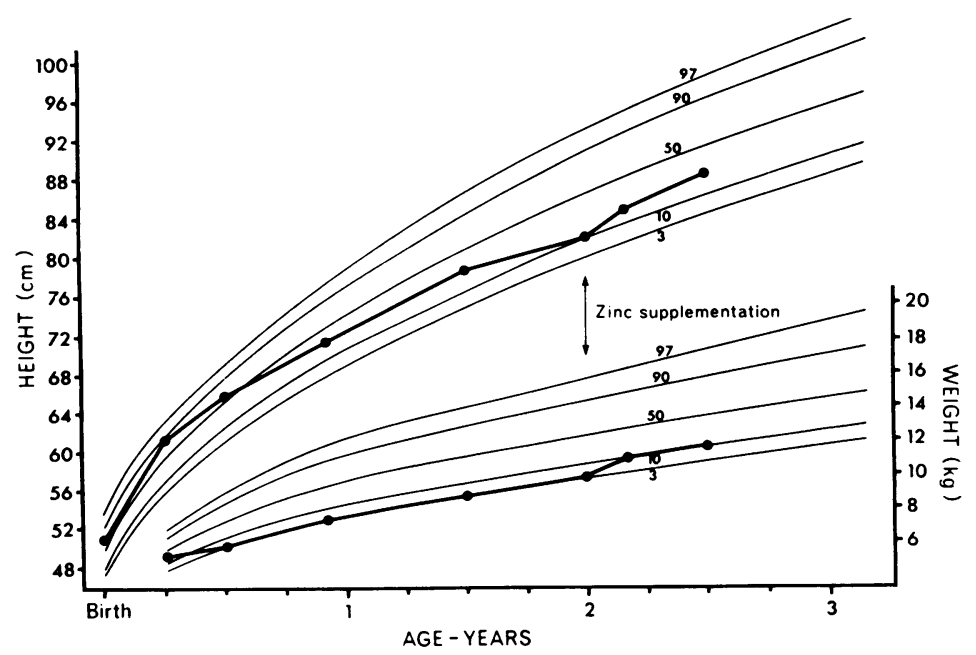

FIG.-Growth centiles before and after zinc supplementation. Centiles based on Harvard School of Public Health and Iowa Child Welfare Research Station data. 
were given once daily for 1 week and then twice daily with meals.

Within 3 days of starting therapy her bizarre manifestations of pica had disappeared completely. An estimate of nutritional intake obtained from her mother indicated that this had approximately doubled during the same time interval, to achieve a daily caloric intake of at least 1200 calories. Between 24 and 30 months of age she gained $7.0 \mathrm{~cm}$ in height and $1474 \mathrm{~g}$ in weight, compared with $2.9 \mathrm{~cm}$ and $936 \mathrm{~g}$, respectively, in the preceding 6-month period. At 30 months of age her height had increased to the 25th centile and her weight to the 10th. The zinc concentration of a $1 \mathrm{~cm}$ length of her hair adjacent to the scalp was 127 p.p.m. at 26 months of age, after 2 months of zinc therapy.

\section{Comment}

The association of poor appetite, low growth centiles, and a low hair zinc level suggested a possible diagnosis of zinc deficiency (Hambidge et al., 1972); the response to dietary zinc supplementation gave further support to this diagnosis. Though the possibility of a placebo effect cannot be discounted, this is considered unlikely in view of her young age and her parents' obvious scepticism when this therapy was offered for their daughter. The quantity of zinc administered each day was small, less than $0.5 \mathrm{mg} / \mathrm{kg}$ body weight, and comparable to calculated daily dietary intakes (Schlage and Wortberg, 1972).

In older children with low hair zinc levels, impairment of taste acuity has been documented (Hambidge et al., 1972). At the age of 2 years the subject of the present report was too young to permit satisfactory objective assessment of her taste acuity. In this context, however, it is of possible significance that her mother spontaneously remarked on her preference for salt and sugar within days of starting zinc therapy.

The factors responsible for zinc deficiency in this subject have not been determined, but there is evidence (Hambidge et al., 1972) to suggest that such a deficiency may not be rare in this age group. The dramatic cessation of her metal-eating habits, which followed almost immediately after starting dietary zinc supplementation, suggests that the possibility of zinc deficiency should be considered in other infants and children exhibiting manifestations of pica.

\section{Summary}

A 2-year-old girl had a 6-month history of pica, manifested by 'metal-eating'. A diagnosis of zinc deficiency was suggested by a history of poor appetite, declining growth centiles, and a low hair zinc level. 3 days after starting oral zinc sulphate
$\left(\mathrm{ZnSO}_{4} \times 7 \mathrm{H}_{2} \mathrm{O} 10 \mathrm{mg} /\right.$ day $)$ she had no further evidence of pica, and it is concluded that this was probably a symptom of zinc deficiency.

This study was supported by Agricultural Research Service, U.S. Department of Agriculture, Grant No. 12-14-100-9941 (61). Also supported in part by USPHS Grant No. RO1-AM12432 from NIAMD, and by a Grant (RR-69) from the General Clinical Research Centers Program of the Division of Research Resources, National Institutes of Health.

\section{REFERENCES}

Halsted, J. A., Ronaghy, H. A., Abadi, P., Haghshenass, M., Amirhakemi, G. H., Barakat, R. M., and Reinhold, J. G. (1972). Zinc deficiency in man: the Shiraz experiment. American Fournal of Medicine, 53, 277.

Hambidge, K. M. (1971). Use of a static argon atmosphere in the emission spectrochemical determination of chromium in biological materials. Analytical Chemistry, 43, 103.

Hambidge, K. M., Hambidge, C., Jacobs, M., and Baum, J. D. (1972). Low levels of zinc in hair, anorexia, poor growth, and hypogeusia in children. Pediatric Research, 6, 868.

Prasad, A. S., Halsted, J. A., and Nadimi, M. (1961). Syndrome of iron deficiency anemia, hepatosplenomegaly, hypogonadism, dwarfism and geophagia. American fournal of Medicine, 31, 532.

Schlage, C., and Wortberg, B. (1972). Zinc in the diet of healthy preschool and school children. Acta Paediatrica Scandinavica, 61, 421.

K. Michael Hambidge, ${ }^{\star}$ and Arnold Silverman Department of Pediatrics, University of Colorado Medical Center, Denver, Colorado, U.S.A.

*Correspondence to Dr. K. M. Hambidge, Department of Pediatrics, University of Colorado Medical Center, 4200 East Ninth Avenue, Denver, Colorado 80220, U.S.A.

\section{Sore bottoms in the newborn}

The occurrence of a sore bottom is relatively common during the first 14 days of life. This study investigated factors which might influence a baby's susceptibility to this condition.

The factors were sex, skin and hair colouring, type of feed, whether bottle or breast fed, and birthweight.

\section{Details of survey}

The survey was carried out from 1 February to 31 May during both 1970 and 1971, the two series involving 50 cases of sore bottoms from 1011 babies.

In the first series 32 cases of sore bottoms were reported out of $\mathbf{3 7 5}$ live births in the old maternity unit known as The Gables. A new maternity unit was opened in the autumn of 1970, and in the second series taken in 1971, 18 cases were reported from the 636 live births in this new unit who were not 48-hour discharges.

All the babies in this study were being nursed normally in the wards with their mothers. No babies being nursed in the special care units were included. None of the babies ever wore plastic pants. Two cases of 